\title{
Desenvolvimento rural e políticas públicas: um estudo de caso no Vale do Ribeira, PR, Brasil
}

\author{
Rural development and public policies: a case study at Ribeira Valley, PR, Brazil
}

\author{
Dayana Lilian Rosa Miranda ${ }^{1}$ \\ Bruno Martins Augusto Gomes ${ }^{2}$
}

\section{Resumo}

Na porção paranaense do Vale do Ribeira (Brasil), encontram-se as mais baixas taxas do Índice de Desenvolvimento Humano - IDH da região. Dessa forma, o governo federal considera o território como sendo uma área composta pelo Território da Cidadania, ou seja, uma região prioritária para a implementação de um conjunto de políticas públicas que visem melhorar as condições de vida da população local. Mediante um estudo de caso no Vale do Ribeira (PR), este artigo tem como objetivo analisar como o desenvolvimento rural de um território é influenciado pelas ações do setor público. Para tanto, foi realizada uma pesquisa bibliográfica e observações in loco, com o intuito de, respectivamente, coletar dados históricos sobre o tema e verificar a condição em que a região se encontra atualmente. Assim, foi possível constatar que o Vale do Ribeira participou de forma marginal dos benefícios do conjunto de políticas públicas direcionado à região, com exceção daqueles produtores mais estruturados e/ou mais integrados ao mercado. A pecuária e o reflorestamento de Pinus e Eucalyptus tiveram um forte incremento nesse período, aumentando ainda mais a concentração fundiária e de renda na região. Pode-se concluir, então, que a agricultura familiar tem relevância no alcance do desenvolvimento rural e sustentável do meio, mas esse êxito é dependente das políticas públicas.

Palavras-chave: Desenvolvimento Rural. Sustentabilidade. Vale do Ribeira.

\begin{abstract}
In the paranaenese porcion of Ribeira Valley (Brazil) are located the most lowest rates of Human Development Index - HDI in the region. Thus, the Federal Governament considers the territory as an area composed by the Citizenship Territory, that's, an prioritary region for a set public policies implementation that aim at to improve the local population life conditions. Through a case study of Ribeira Valley, this article has as goal to analyze how the rural development of a territory is influenced by the public sector actions. Therefore, was accomplished a bibliographic search and onsite observations, in order to, respectively, to collect historical data about the theme and to verify the current territory conditions. Thereby, was possible to find out that the Ribeira Valley participated marginally of the public policies benefits directed to the region, with the exception of those more structured producers and / or more integrated to the market. The livestock and the reforestation of pine and eucalyptus had an increase strong in this period, further increasing land and income concentration in the region. Thus, we can conclude that the family farming has relevant
\end{abstract}

\footnotetext{
${ }^{1}$ Mestre em Planejamento Territorial e Desenvolvimento Socioambiental (UDESC). E-mail: dayana.1.rosa@gmail.com.

${ }^{2}$ Doutor em Políticas Públicas (UFPR). Professor do Programa de Pós-graduação em Turismo da UFPR.
}

Guaju, Matinhos, v.2, n.2, p. 75-88, jul./dez. 2016 
in order to achieve the rural and sustainable environment development, but this success is dependent of the public policies.

Keywords: Rural Development. Sustainability. Ribeira Valley.

\section{Introdução}

Segundo Navarro (2001), durante muito tempo o desenvolvimento rural foi associado ao conjunto de ações do Estado e de organismos internacionais destinados a intervenções nas regiões rurais pobres que não conseguiam se integrar ao processo de modernização agrícola, preconizando ações de intervenção dirigidas e orientadas sob um caráter compensatório. Essa realidade se fez presente na região do Vale do Ribeira (PR), que conta com ricos patrimônios ambientais e culturais, porém acusa baixa qualidade de vida e desenvolvimento econômico em função das características geográficas e das opções de políticas públicas vinculadas à região.

O território do Vale do Ribeira está localizado na Bacia Hidrográfica Ribeira do Iguape e no Complexo Estuarino Lagunar de Iguape-Cananeia-Paranaguá, abrangendo as regiões sudeste do estado de São Paulo ${ }^{3}$ e leste do estado do Paraná. A região paranaense é composta por sete municípios: Adrianópolis, Bocaiúva do Sul, Cerro Azul, Doutor Ulisses, Itaperuçu, Rio Branco do Sul e Tunas do Paraná.

Esse território tem sua base econômica atrelada principalmente à agricultura familiar - com predomínio de culturas de milho, feijão e mandioca, bem como ao extrativismo vegetal e mineral. A agricultura ocupa $30 \%$ do território, emprega $70 \%$ da mão de obra, gera $60 \%$ da arrecadação municipal e contribui com cerca de $20 \%$ para o Produto Interno Bruto - PIB regional (IPARDES, 2011). Mas na região do Vale do Ribeira estão as mais baixas taxas do Índice de Desenvolvimento Humano, apresentando um IDH médio de 0,69 - o que a faz ser considerada pelos governos estadual e federal como prioritária para a implementação de um conjunto de políticas públicas que visem melhorar as condições de vida da população local.

Dessa forma, este artigo tem como objetivo analisar como o desenvolvimento rural de um território é influenciado pelas ações do setor público mediante um estudo de caso do Vale do Ribeira. Para tanto, em termos metodológicos, foi realizada uma pesquisa qualitativa adotando a

\footnotetext{
${ }^{3}$ A região do Vale do Ribeira paulista é formada por 24 municípios (Apiaí, Juquiá, Cananeia, Cajati, Itariri, Registro, Jacupiranga, Tapiraí, Pedro de Toledo, Barra do Chapéu, Iguape, Eldorado, Itapirapuã Paulista, Miracatu, Ribeirão Grande, Ribeira, Barra do Turvo, Ilha Comprida, Iporanga, Taóca, Juquitiba, Pariquera-Açú, São Lourenço da Serra e Sete Barras), contendo áreas de parques e reservas naturais de Mata Atlântica declaradas pela Unesco como reserva da biosfera. Disponível em: <www.saopaulo.sp.gov.br>.
} 
análise bibliográfica e a observação in loco, com o intuito de, respectivamente, coletar dados históricos sobre o tema e constatar a condição em que esse território se encontrava. Segundo Dencker (2001, p. 97), “a metodologia qualitativa permite uma análise das causas, condições e frequência de determinadas situações sociais, permitindo a compreensão de problemas, estruturas, sistemas e processos".

Como estratégia de pesquisa, optou-se por adotar a abordagem de estudo de caso, pelo fato desta ser uma estratégia de investigação em que o pesquisador explora profundamente um programa, um evento, uma atividade ou um processo (CRESWELL, 2010).

A coleta dos dados foi feita através de um roteiro de entrevistas juntamente com a gravação delas, seguido da transcrição literal das informações e complementadas pelo diário de campo. A técnica de recolhimento de dados se deu sob a forma de entrevistas semiestruturadas. Os dados foram coletados com agricultores e agricultoras familiares, gestores intermediários dos programas de governo em vigência e com o poder público local, representando esses atores-chaves lideranças comunitárias de agricultores familiares e técnicos/servidores públicos relacionados à área, totalizando 29 entrevistas com sujeitos ligados à agricultura familiar local. Então, foi elaborada a análise dos dados coletados, a qual é exposta a seguir pautando-se em um resgate das principais políticas públicas que impactaram no desenvolvimento rural do território.

Por fim, expõe-se uma síntese dessa relação entre as ações implementadas pelo setor público e o desenvolvimento rural alcançado a partir da experiência do Vale do Ribeira, assim como são apresentadas propostas para pesquisas futuras comprometidas com a temática.

\section{Desenvolvimento Rural}

Navarro (2001) expõe que o "conceito de desenvolvimento rural se altera ao longo do tempo, influenciado por diversas conjunturas e, principalmente, pelos novos condicionantes que o desenvolvimento mais geral da economia e da vida social gradualmente impõem às famílias e às atividades rurais". Ainda segundo o autor:

Desenvolvimento rural, portanto, pode ser analisado a posteriori, neste caso referindo-se às análises sobre programas já realizados pelo Estado (em seus diferentes níveis) visando alterar facetas do mundo rural a partir de objetivos previamente definidos. Mas pode se referir também à elaboração de uma "ação prática" para o futuro, qual seja, implantar uma estratégia de desenvolvimento rural 
para um período vindouro (assim, existiriam diversas metodologias de construção de tal estratégia, bem como um amplo debate sobre seus objetivos e prioridades principais) (NAVARRO, 2001, p. 88).

Entende-se por desenvolvimento rural a melhoria das condições de vida das pessoas residentes nas áreas e regiões rurais, através de processos sociais que respeitem e articulem os princípios de eficiência econômica, equidade social e territorial, qualidade patrimonial e ambiental, sustentabilidade, participação democrática e responsabilidade cívica (BRASIL, 2003).

Conforme Moreira e Carmo (2004), o termo desenvolvimento rural foi disseminado notadamente na década de 1970, como estratégia para contrabalançar os efeitos negativos da modernização da agricultura que incidia sobre os países do terceiro mundo, convergindo com o modelo de "desenvolvimento comunitário" amplamente aplicado pelas agências internacionais de desenvolvimento durante as décadas de 1950 e 1960. Já na década de 1980, eis que surge então outro intento modernizador revolucionário, agora implementado por meio de técnicas e estruturas de difusionismo mais agressivas e integradas. Era o Desenvolvimento Rural Integrado, que surgia a partir de teorias sociológicas, antropológicas e econômicas da modernização agrária, com base nas premissas de que: 1) a causa da pobreza rural nos países subdesenvolvidos era a carência de tecnologias adequadas às suas circunstâncias e à falta de capital humano para realizar a mudança tecnológica; 2) o responsável por essa carência de capital humano era a falta de investimentos em pesquisa, experimentação agrícola e educação rural; e 3) a falta de investimentos devia-se às políticas nacionais que não valorizavam a agricultura (MOREIRA; CARMO, 2004).

No Brasil, nos anos de 1990, a sustentabilidade foi incorporada às estratégias de desenvolvimento rural, sob a forma de programas de desenvolvimento rural sustentável, agora mediante a industrialização sustentável da agricultura (MOREIRA; CARMO, 2004). Schneider (2010) acredita que, a partir desse período, as políticas públicas e discussões teóricas sobre o desenvolvimento rural reemergiram em bases inteiramente diferentes daquelas da década de 1970 . Sob influência das transformações sociais, políticas e econômicas que se operaram no âmbito do Estado brasileiro, as discussões específicas sobre o tema do desenvolvimento rural e as políticas governamentais voltaram-se para a reforma agrária, crédito para agricultura familiar, segurança alimentar, combate às formas precárias de trabalho, regularização fundiária, apoio às populações tradicionais (quilombolas, ribeirinhos) e ações de desenvolvimento territorial.

Porém, Moreira e Carmo (2004) destacam a também presente estratégia de industrializar sustentavelmente a agricultura, gerando um modelo hegemônico que padroniza o manejo industrial 
dos recursos naturais, sem levar em consideração as especificidades de cada país, território, região ou lugar. Altieri (2002) esclarece que tal forma de manejo é incompatível com o conceito de sustentabilidade ecológica, pois a agricultura industrializada transforma os ciclos naturais e os processos biológicos, forçando as bases da reprodução biótica do ar, da água e da terra. Assim, entende-se como Desenvolvimento Rural Sustentável (DRS) um conjunto de práticas e tecnologias aplicadas ao meio rural que possibilite a exploração e utilização racional dos recursos naturais com o menor impacto possível, propiciando a sustentabilidade do meio também para as gerações futuras (ALTIERI, 2004).

Segundo Maluf (2001), a temática territorial permitiu a emergência, na definição de políticas públicas, de um discurso de revalorização do meio rural, antes negligenciado em ações de desenvolvimento regional, que eram basicamente voltadas para a estruturação dos espaços urbanos. O meio rural deixa de ser entendido somente por suas características produtivas e passa a ser valorizado também por seus aspectos sociais, culturais e ambientais, assim como o posicionamento contrário à dicotomia rural-urbano, que negligencia as relações sociais desenvolvidas na prática em decorrência dos diversos mecanismos de integração entre esses espaços.

De acordo com o Ministério do Desenvolvimento Agrário (MDA, 2003), as políticas de desenvolvimento territorial devem levar em consideração as quatro dimensões elementares do desenvolvimento, quais sejam: (i) economia; (ii) sociedade e cultura; (iii) ambiente; e (iv) política e instituições, sendo necessário entender os processos de desenvolvimento como algo que envolve múltiplas dimensões, cada qual contribuindo de uma determinada maneira para o futuro e a sustentabilidade do território.

Abramovay (2010) acrescenta que a concepção de território abre caminho para um avanço notável na concepção do estudo do desenvolvimento, visto a ênfase na maneira de como os diferentes atores - públicos, privados e sociedade civil organizada - relacionam-se no plano local. Martins (2009) discute a abordagem que se refere ao desenvolvimento e regulação socioambiental dos territórios rurais a partir de esferas públicas de governança política das áreas rurais que venham a representar, além dos interesses agrícolas, os demais setores sociais ligados à dinamização e otimização das economias locais e regionais e à preservação da cultura.

Fox (1990), Navarro (1999, 2002) e Martins (1999, 2003) indicam que os processos de desenvolvimento ligados à participação e organização popular podem e devem contribuir efetivamente para estimular a "emancipação social", criar mecanismos de responsabilização 
(accountability) e promover a democratização da sociedade, a participação dos atores e a coesão social e territorial.

No entanto, Schneider (2010) sustenta a afirmativa de que a formulação da agenda de ações do Estado é menos influenciada pelos demandantes diretos das políticas, no caso, os agricultores e as populações rurais, do que pelos estudiosos e mediadores. $\mathrm{O}$ autor relata que a agenda de questões que formam as políticas de desenvolvimento rural do Estado brasileiro desde a década de 1990 é permeada pelas ideias e propostas colhidas pelos formuladores de políticas (police makers) junto com estudiosos e mediadores.

Cazella (2012) defende uma formulação de políticas públicas de desenvolvimento rural mais próxima das propostas do desenvolvimento territorial, ou seja, contemplando: (i) ações permanentes de reassentamentos de famílias para o alcance do reordenamento territorial e fundiário - reforma agrária e crédito fundiário; (ii) microfinanças; (iii) pluriatividade - exercício de outras atividades remuneradas associadas à agricultura; e (iv) a valorização do caráter multifuncional da agricultura familiar - segurança alimentar, conservação ambiental, manutenção de paisagens rurais, geração de novas ocupações, entre outros.

Nesse sentido, Abramovay (2010) argumenta que num país marcado pela tradição latifundiária como o Brasil, o acesso à terra, ao crédito e ao mercado são fundamentais para o processo de desenvolvimento rural. Como exposto por Guimarães (1977), o latifúndio é o grande responsável pelo atraso no campo - afinal, este apresentava baixos índices de produtividade e altos índices de exploração dos trabalhadores rurais.

Em suma, acredita-se que os estudos sobre o desenvolvimento rural no Brasil precisam buscar uma maior emancipação do modelo de desenvolvimento adotado a partir das ações do Estado, das políticas públicas e até mesmo da participação social, em vias de atingir uma perspectiva real da necessidade emergencial dos processos de mudança social.

\section{Desenvolvimento Rural e políticas públicas no Vale do Ribeira}

O Vale do Ribeira (PR) conta, a partir dos anos 1970, com um conjunto de ações de programas governamentais que dão ênfase para a agricultura da região. Dentre as políticas públicas implantadas na região anteriormente, merece destaque o Programa Integrado de Desenvolvimento do Litoral e Alto Ribeira - Prodelar, criado em 1976 pelo governo do Paraná, que objetivava 
sumariamente o desenvolvimento da região Litoral e Alto Ribeira (BIANCHINI, 2010). Esse programa não via na atividade um potencial projeto voltado ao desenvolvimento "econômico" da região, por isso ele priorizou a atividade de pesquisa e exploração mineral como sendo uma atividade econômica com potencial para o alcance do então desenvolvimento econômico do território. Segundo a mesma fonte, dentre as políticas de médio e longo prazo, foram previstas a criação de um polo cimenteiro na região e, em segundo plano, o aproveitamento da laranja em Cerro Azul. Como políticas de curto prazo, de forma marginal foi previsto o apoio à agricultura em cadeias como a do leite, fruticultura (mamão e citrus), olericultura (tomate, pimentão e alho) e as culturas de subsistência, além de um programa de regularização fundiária dos municípios que compõem o território.

Porém, a fragilidade da assistência técnica e do investimento em pesquisa, a ausência de cooperativas, bancos, agroindústrias, bem como canais de mercado e meios de escoamento da produção impossibilitaram a consolidação de cadeias como a da hortifruticultura, a do leite e da laranja (BIANCHINI, 2010). Já a prioridade do Prodelar, que era investir em pesquisa e exploração mineral, acabou se concretizando quando subsídios governamentais foram destinados à pesquisa e exploração mineral, acarretando no fortalecimento e ampliação do polo cimenteiro nos municípios de Itaperuçu e Rio Branco do Sul.

Souza (1976) expõe que, frente às limitações impostas pelo relevo do território, fortaleceu-se, na década de 1970, uma outra atividade econômica impulsionada pelos incentivos fiscais promovidos pelo governo federal na região do Vale do Ribeira (PR), sendo estes revertidos para plantios comerciais de madeira de reflorestamento de Pinus e Eucalyptus, tendo em vista que a área não seria supostamente adequada para a agricultura mecanizada. Destaca-se que, naquele período, tem-se o processo de modernização da agricultura no Brasil como um marco histórico no que tange ao desenvolvimento do setor agrícola nacional. Souza (1976) afirma ainda que com a implantação das áreas de reflorestamento muitas comunidades e porções de área rural de municípios inteiros acompanharam a desconfiguração do verde da Mata Atlântica presente no Vale do Ribeira, causada pela ação do vento e do homem. Nos municípios de Rio Branco do Sul e Itaperuçu o reflorestamento das espécies é mais significativo e recorrente.

Na década de 1980, tem-se o surgimento do Programa de Apoio à População Carente do Alto Ribeira - Pró-Ribeira, criado como parte integrante do Programa de Desenvolvimento Regional - Apoio às Populações Carentes, elaborado pelo Instituto Paranaense de Desenvolvimento Econômico e Social (Ipardes) e financiado por agências multilaterais de desenvolvimento 
(BIANCHINI, 2010). A proposta era a promoção do incentivo à melhoria da produção de culturas de subsistência, como o milho e o feijão, aos novos implementos agrícolas de tração animal, à citricultura, à pecuária (leite, caprinocultura e suinocultura). O programa trabalhava ainda as temáticas de apicultura, armazenagem, comercialização, melhoria de estradas, regularização fundiária, saneamento rural e até mesmo a diversificação da pequena propriedade a partir do reflorestamento de Pinus ou Eucalyptus e/ou Bracatinga ou erva-mate em áreas impróprias à agricultura em até três hectares da propriedade. O resultado revelou que a diversificação agropecuária foi modesta, ao passo que o reflorestamento de Pinus e Eucalyptus foi significativo, principalmente no que tange aos municípios de Itaperuçu e Rio Branco do Sul.

Ainda na década de 1980 ocorreu o Projeto Integrado de Apoio ao Pequeno Produtor Rural (Pró-Rural), criado em 1981 pelo governo do estado do Paraná com apoio do Banco Interamericano de Desenvolvimento (BID), visando à ampliação da estrutura da Assistência Técnica Rural (Ater), da pesquisa, do apoio ao associativismo, criação de associações e melhora de infraestrutura e dinamização do uso do crédito rural (BIANCHINI, 2010). O Pró-Rural tinha o objetivo de aumentar a produção agropecuária, o nível de renda dos produtores e, consequentemente, a qualidade de vida. Como resultado, o programa proporcionou um incremento às principais cadeias produtivas da região, com um baixo alcance no universo dos pequenos agricultores, beneficiando, portanto, agricultores com melhor nível de tecnologia. Porém, o impacto mais significativo que se pode atribuir ao Pró-Rural foi a recuperação da "máquina estatal" durante os anos 1980, dando a ela condições de operacionalidade através da criação de novos escritórios da Empresa de Assistência Técnica e Extensão Rural (Emater), com a consequente ampliação no número de técnicos, veículos e rede de apoio à pesquisa na agricultura.

Ainda segundo Bianchini (2010), em 1989 é implementado o Programa de Manejo das Águas, Conservação do Solo e Controle da Poluição em Microbacias Hidrográficas - Paraná Rural. Este previa a conservação de solos e da água e o controle da poluição, além de confirmar a microbacia hidrográfica como unidade de planejamento e ação prioritária para as regiões mais dinâmicas da agricultura e uma das mais impactadas pelo uso intensivo do solo. Esse novo programa foi priorizado em relação ao Pró-Rural. Assim, fora optado pelas áreas mais férteis e dinâmicas do estado, que são as regiões norte e oeste, com uma agricultura mais intensiva e uma maior demanda de manejo do solo e da água, bem como de controle da poluição. Logo, os investimentos do Paraná Rural no Vale foram proporcionais à importância econômica da região e à 
capacidade de contrapartida de seus agricultores, ou ainda, à adequação da tecnologia e da assistência técnica à realidade regional, recebendo o território, assim, poucos recursos.

Com o término do Pró-Rural é criado então, em 1998, o Paraná 12 Meses, executado pelo governo do estado com apoio financeiro do Banco Mundial, estando em atividade até abril de 2006. Os componentes básicos do programa previam o desenvolvimento social e produtivo do beneficiário e o fortalecimento institucional e desenvolvimento tecnológico. Em sua concepção, o programa se pautava na viabilização da agricultura a partir dos agricultores e seus familiares, como cidadãos e profissionais da agricultura. O Paraná 12 Meses propunha avançar nos hortifrutigranjeiros e na revitalização da cafeicultura, além de agregar mais valor à produção com o incremento da agroindustrialização, traduzidas em um plano de ação. Porém, o programa favoreceu agricultores localizados em áreas mais férteis com sistemas mais intensivos, o que não era o caso do Vale do Ribeira. O apoio à agricultura foi pequeno, não atendendo novamente às reais demandas dos agricultores familiares da região, principalmente os de menor renda. Em relação ao meio ambiente, faltou a adequação das propostas técnicas do programa às reais necessidades dos agricultores e da região (BIANCHINI, 2010).

Nas duas primeiras décadas do século XXI encontram-se disponíveis para acesso por parte dos agricultores as seguintes políticas públicas voltadas para a manutenção, apoio e desenvolvimento da agricultura familiar: o (i) Programa Nacional de Fortalecimento da Agricultura Familiar - Pronaf, que objetiva fortalecer as atividades desenvolvidas pelo produtor familiar por meio da integração do agricultor com a cadeia produtiva; (ii) Programa de Aquisição de Alimentos - PAA, que visa adquirir produtos da agricultura familiar para formação de estoques de alimentos, controlar preços e realizar doações simultâneas para famílias e grupos sociais em situação de insegurança alimentar; o (iii) Programa Nacional de Alimentação Escolar - Pnae, que oferta refeições balanceadas e nutritivas a estudantes da rede pública de ensino; o (iv) Programa Nacional de Apoio ao Médio Produtor Rural - Pronamp, que é voltado ao médio produtor rural, sendo financiamentos cedidos quando a renda do agricultor ultrapassa o valor máximo de investimento estabelecido pelo Pronaf; o (v) Programa de Garantia da Atividade Agropecuária - Proagro, que consiste em um seguro da safra; o (vi) Finame Agrícola, que consiste no auxílio via crédito à produção e à comercialização de máquinas, implementos agrícolas, bens de informática e automação destinados à produção agropecuária; e, por fim, o (vii) ABC da Agricultura de baixo carbono, que é uma linha de crédito que tem como objetivo incentivar a adoção de técnicas 
agrícolas sustentáveis que contribuam para a redução das emissões de gases de efeito estufa e para a preservação dos recursos naturais.

Contudo, o território do Vale do Ribeira participou de forma marginal desse processo, em se tratando do desenvolvimento regional que tais políticas públicas implementadas poderiam ter trazido ao território, embora produtores mais estruturados e/ou mais integrados ao mercado tenham se beneficiado diretamente desde as últimas décadas do século XX. A pecuária e o reflorestamento de Pinus e Eucalyptus tiveram um forte incremento nesse período, aumentando ainda mais a concentração fundiária e de renda na região.

Os pequenos agricultores da região relatam que antes da década de 1970 a economia agrícola local era boa, mas que os modos de produção eram um tanto quanto sofridos para o agricultor. Após esse período veio uma crise para a agricultura local, com uma queda significativa nos preços e a desvalorização dos principais produtos destinados à comercialização (milho, feijão e mandioca), acarretando no abandono das atividades da lavoura e grande êxodo rural nos municípios por conta do fato. Grande parcela dos agricultores que permaneceram no campo arrendou suas terras para plantações de Pinus e Braquiária para o gado, fato que acarretou no empobrecimento e infertilidade do solo. Com isso, intensificaram-se os processos de queimada e inserção de adubos químicos e/ou sintéticos no solo, o que somou para um maior empobrecimento, aceleração de processos de erosão e infertilidade dos solos cultiváveis da região.

Os agricultores familiares, sem maiores opções, se inseriram crescentemente na dinâmica do mercado - a monocultura extensiva do Pinus e Eucalyptus, fato que acarretou na perda de autonomia do processo produtivo, forçando muitos deles a migrarem para outros locais. Muitos agricultores familiares ainda não têm acesso à regularização fundiária de suas propriedades, o que dificulta o acesso a um conjunto de políticas públicas como o crédito rural, habitação e subsídios governamentais via projetos de desenvolvimento rural, sem falar na produção agrícola, que depende do acesso à terra para ser desenvolvida.

Há um consenso presente nas falas dos locais de que a agricultura nos municípios estaria acabando devido ao envelhecimento das pessoas que habitam o campo. Segundo relatos, está permanecendo no meio rural somente os pais e avós daqueles que foram nascidos e criados na roça, estando a juventude a migrar para os polos urbanos. Destaca-se que, por conta dos efeitos negativos que o cultivo do Pinus e Eucalyptus traz ao solo, atrelado ainda à forte extração de minérios presente na região, a atividade agrícola ficará ainda mais comprometida. Nesse sentido, os sujeitos 
envolvidos citam a necessidade de "corrigir os erros do passado" através da recuperação do solo e utilização do manejo orgânico e agroecológico na cultura de produção.

Contudo, segundo os atores entrevistados, a partir do início dos anos 2000, a realidade do Vale do Ribeira obteve melhoras com a criação das entidades representativas de classe, a utilização de maquinário no campo nas áreas apropriáveis, a facilitação do transporte da mercadoria produzida, a diversificação da produção para subsistência e comercialização e o acesso por parte dos agricultores familiares às políticas públicas e programas de governo tratados no presente estudo.

Como possíveis soluções para aperfeiçoar a agricultura local foram citadas questões inerentes à recuperação das práticas antigas de mutirões (puxirões); à permanência dos programas atuais de governo; ao aumento das cotas e criação de novos programas em prol do benefício do setor, independente da mudança de governo; à ampliação dos canais de mercado; à melhoria na logística de comercialização e valorização dos preços dos produtos; ao desenvolvimento de agroindústrias locais, para beneficiar e processar os alimentos produzidos localmente; à profissionalização do meio rural através da oferta de capacitação, principalmente para os jovens; ao estímulo à produção orgânica e agroecológica; e à facilidade de acesso à certificação dos produtos, assim como a melhoria na assistência técnica de produção.

Portanto, sob o ponto de vista adotado na presente pesquisa, tem-se que a modernização da agricultura representou o processo pelo qual o progresso tecnológico se internalizou na agricultura, modificando o tipo de relação que o agricultor estabelecia com a natureza e os sistemas produtivos, mostrando desarticulação dos sistemas de valores preexistentes e o abandono de formas tradicionais de sociabilidade em comunidades tradicionais, como por exemplo, os mutirões ligados à produção e colheita dos alimentos e a dinâmica do movimento de trocas entre os produtores. Nota-se também que os agricultores que não tinham acesso à terra e a outros recursos produtivos não se ajustaram às condições do modelo vigente, permanecendo a grande maioria fora da dinâmica de “desenvolvimento rural".

Em suma, a lógica operacionalizada a partir das políticas públicas vistas em campo, precisamente na região estudada, revela uma perspectiva de reintegração e fortalecimento da produção de alimentos a nível local, propiciando aos agricultores familiares estratégias antes não acessadas de subsídios de produção e comercialização, de modo a estruturar condições que permitirão a comercialização através de outros instrumentos locais e regionais. As atuais políticas públicas em vigência nos municípios revelam uma garantia das condições de manutenção do agricultor familiar no campo, trazendo benefícios em termos econômicos e de ressignificação das 
relações internas e externas da lógica familiar, representando um instrumento de "subsídio" da agricultura familiar com foco na produção de alimentos para o consumo local.

\section{Considerações Finais}

Em um país marcado pela visível tradição latifundiária como o Brasil, o acesso a terra, ao crédito, ao mercado e todos os subcomponentes implícitos no processo consistem em iniciativas primordiais para a composição do alcance do desenvolvimento para as populações residentes no meio rural. Nesse cenário, políticas públicas voltadas para o fortalecimento da agricultura familiar possibilitam novos rumos para o alcance do desenvolvimento rural com equidade social e melhoria na qualidade de vida dos agricultores. Portanto, este texto teve o objetivo de analisar como o desenvolvimento rural de um território é influenciado pelas ações do setor público mediante um estudo de caso do Vale do Ribeira.

Ficou evidente que está institucionalizado entre os tomadores de decisão do setor público a formulação de políticas públicas voltadas para a região do Vale do Ribeira, porém, estas pouco alcançam a promoção do desenvolvimento sustentável desse território. Algumas, como as relacionadas à pecuária e ao reflorestamento de Pinus e Eucalyptus inclusive aumentaram a concentração fundiária e de renda na região. Da mesma forma, é comum estas gerarem benefícios para alguns produtores mais estruturados e/ou mais integrados ao mercado.

Como implicação teórica, este artigo expõe a relevância da agricultura familiar para o alcance do desenvolvimento rural e sustentável do meio, realçando a dependência desses objetivos em relação às políticas públicas e agricultura na discussão e redimensionamento do modelo predominante de desenvolvimento rural. O mesmo processo que gerou a exclusão e o abandono do campo por famílias de agricultores de pequena escala também foi responsável pelo surgimento de uma nova dinâmica no campo, que vem apontando caminhos considerados viáveis como solução para uma permanência digna de homens e mulheres no meio rural por meio da agricultura familiar. Desde os anos 1990, vem surgindo uma legitimação desta como estratégia de desenvolvimento rural sustentável e no cenário político que envolve o setor.

Como implicação prática, defende-se a importância dos agricultores familiares organizados sob a forma de modelo baseado nos moldes cooperativos/associativos sistematizarem suas formas de produção e comercialização. Essa articulação se constituirá como um veículo de 
comercialização, mas também como uma ferramenta de politização dos agricultores de base familiar, de desenvolvimento de processos culturais de produção orgânica e agroecológica. Portanto, funcionará como um estímulo do desenvolvimento rural a partir do local.

Finalmente, pesquisas futuras podem dedicar-se à investigação com os diversos sujeitos envolvidos acerca de uma possível mudança de enfoque na aplicação das políticas públicas em curso, de modo a criar condições que alterem o ambiente institucional local e regional. Com isso, poderiam ser reveladas as potencialidades presentes, criando-se de forma conjunta estratégias que possam vir a ter implicações no desenvolvimento e na definição de políticas públicas e diretrizes de planejamento e gestão ligadas ao desenvolvimento rural sustentável, de forma a organizar os processos político-institucionais da agricultura familiar e sua dinâmica socioprodutiva local e regional.

Cita-se ainda como lacuna de pesquisa o não mapeamento da distribuição espacial das políticas públicas em curso, ocasionado pela insuficiência de dados disponíveis, seguido da impossibilidade de categorização de acesso através de um mapa ilustrativo que mostrasse a realidade in loco dos principais perfis de beneficiários, as comunidades em que estão situados, se são residentes ou não, as principais atividades agropecuárias envolvidas, entre outros, representando uma ferramenta que possibilitaria gerar um diagnóstico atual das políticas públicas em curso e até mesmo um prognóstico e/ou cenário ideal baseado nos dados coletados em campo.

\section{Referências}

ABRAMOVAY, R. Para uma Teoria dos Estudos Rurais. In: VIEIRA, P. et al. (Orgs.). Desenvolvimento Territorial Sustentável no Brasil: subsídios para uma política de fomento. Florianópolis: Secco, 2010.

ALTIERI, M. Agroecologia: a dinâmica produtiva da agricultura sustentável. 4. ed. Porto Alegre: UFRGS, 2004.

BIANCHINI, V. O Programa Nacional de Fortalecimento da Agricultura Familiar - PRONAF e a sustentabilidade da agricultura no Vale do Ribeira - Paraná. Tese de Doutorado Universidade Federal do Paraná, Programa de Pós-Graduação em Meio Ambiente e Desenvolvimento. Curitiba, 2010.

BRASIL. Ministério de Desenvolvimento Agrário (MDA). Referências para o Desenvolvimento Territorial Sustentável. Brasília: MDA/SDT, Condraf, 2003.

CAZELlA, A. A. Agricultura familiar: ainda é possível se diferenciar? Observatório de Políticas Públicas para a Agricultura, n. 43, ago. 2012. 
CRESWELL, J. W. Projeto de pesquisa: métodos qualitativo, quantitativo e misto. 3. ed. Porto Alegre: Artmed, 2010.

DENCKER, A. F.M. Métodos e técnicas de pesquisa em Turismo. 5. ed. São Paulo: Futura, 2001.

FOX, J. Democratic rural development: leadership accountability in regional peasant organizations. Developmentand Change, v. 23, n. 2, 1990.

GUIMARÃES, A. P. Quatro séculos de latifúndio. Rio de Janeiro: Paz e Terra, 1977.

IPARDES. Instituto Paranaense de Desenvolvimento Econômico e Social. Municípios e Regiões. Caderno 2011. Disponível em: <www.ipardes.gov.br>. Acesso em: 20 nov. 2015.

MALUF, R. Políticas agrícolas e de desenvolvimento rural e a segurança alimentar. In: LEITE, Sérgio (Org.). Políticas públicas e agricultura no Brasil. Porto Alegre: UFRGS, 2001.

MARTINS, J. S. O poder do atraso. Ensaios de sociologia da história lenta. 2. ed. São Paulo: Hucitec, 1999.

MARTINS, J. S. O sujeito oculto. Ordem e transgressão na reforma agrária. Porto Alegre: UFRGS, 2003.

MARTINS, R. C. Descrição e prescrição no desenvolvimento rural: o território como espaço social reificado. Ruris, v., n. 1, mar. 2009.

MOREIRA, R. M.; CARMO, Maristela Simões do. Agroecologia na construção do Desenvolvimento Rural Sustentável. Agricultura São Paulo, v. 51, n. 2, p. 37-56, jul./dez. 2004.

NAVARRO, Z. Manejo de recursos naturais e desenvolvimento rural: um estudo comparativo em quatro estados brasileiros (lições e desafios). Relatório ao Banco Mundial, 1999.

NAVARRO, Z. Desenvolvimento rural brasileiro: os limites do passado e os caminhos do futuro. Revista Estudos Avançados, v. 15, n. 43, p. 83-100, set./dez. 2001.

NAVARRO, Z. Mobilização sem emancipação: as lutas sociais dos sem terra no Brasil. In: SANTOS, B. S. (Org.). Produzir para viver: os caminhos da produção não capitalista. São Paulo: Civilização Brasileira, 2002.

SCHNEIDER, S. Situando o desenvolvimento rural no Brasil: o contexto e as questões em debate. Revista de Economia Política, v. 30, n. 3, p. 511-531, jul./set. 2010.

SOUZA, D. M. P. Alterações físicas, químicas e biológicas provocadas pela cultura de Pinus em alguns solos do Paraná. Curitiba: SCA UFPR, 1976 (mimeografado).

Artigo recebido em 13/11/2016. Aceito para publicação em 13/12/2016.

Guaju, Matinhos, v.2, n.2, p. 75-88, jul./dez. 2016 